\title{
A study of Candida albicans and non-albicans Candida species isolated from various clinical samples and their antifungal susceptibility pattern \\ Ratna Shukla ${ }^{1, *}$, Sukrutha Gopal Reddy ${ }^{1}$ and Anil Kumar Bilolikar ${ }^{1}$ \\ ${ }^{1}$ Department of Microbiology, Krishna Institute of Medical Sciences, Minister Road, Secunderabad-500003, Telangana, India
}

\begin{abstract}
Background: Candida species are the most common cause of fungal infections worldwide. Candida albicans has been the most common causative agent until recent past but frequency of non-albicans Candida (NAC) species is on the rise. This changing epidemiology and increase in resistance to antifungal agents makes it important to identify Candida up to the species level and know its antifungal susceptibility pattern.
\end{abstract}

Aim: To provide data on Candida species prevalence and to highlight the need of speciation of Candida and its antifungal susceptibility testing.

Material and methods: For blood cultures, BacT/ALERT blood culture automated system (BioMérieux) was used. Candida was identified initially by direct microscopic examination of samples received and culture was done on SDA with antibiotic. Differentiation of Candida albicans and NAC species was done by germ tube test and final identification and antifungal susceptibility testing were done using Vitek 2 compact.

Result- The prevalence of Candida infection in this study is 1.58\%. Out of total 100 Candida isolates, $25 \%$ were C.albicans and 75\% were NAC. Among 75 non-albicans Candida spp.; C.tropicalis (46) forms the major isolate. Other NAC spp. included C.hemulonii (9), C.glabrata (6) \& others (14). C.albicans is found to be more susceptible to fluconazole as compared to NAC spp. In this study NAC species showed comparatively reduced susceptibility to fluconazole and amphotericin B.

Conclusion: There is a significant epidemiological shift in candidiasis cases due to NAC species. Based on the present results and trends, it becomes essential to routinely identify Candida isolates up to species level, and detect evolving resistant strains by antifungal susceptibility testing wherever feasible.

Keywords: Non-albicans Candida; Candida auris; emerging infection; antifungal resistance

*Corresponding author: Dr. Ratna Shukla, Department of Microbiology, Krishna Institute of Medical Sciences, Minister Road, Secunderabad-500003, Telangana, India. Email: ratnashukla8@ gmail.com

Received 06 November 2019; Revised 14 December 2019; Accepted 23 December 2019; Published 30 December 2019

Citation: Shukla R, Reddy SG, Bilolikar AK. A study of Candida albicans and non-albicans Candida species isolated from various clinical samples and their antifungal susceptibility pattern. J Med Sci Res. 2020; 8(1):1-11. DOI: http://dx.doi.org/10.17727/ JMSR.2020/8-1

Copyright: (c) 2020 Shukla R et al. Published by KIMS Foundation and Research Center. This is an open-access article distributed under the terms of the Creative Commons Attribution License, which permits unrestricted use, distribution, and reproduction in any medium, provided the original author and source are credited. 


\section{Introduction}

Candida species are the most common cause of fungal infections worldwide [1]. C.albicans is the most common causative agent of candidiasis; but its incidence is declining and the frequency of other non-albicans Candida (NAC) species is increasing [2]. The genus Candida consists of about 200 species and around 20 distinct Candida species are known to cause human disease. More than $90-95 \%$ of invasive disease is caused by 5 most common pathogens, namely: C.albicans, C.tropicalis, C.glabrata, C.parapsilosis and C.krusei [3, 4].Candida being a significant opportunistic pathogen; causes a wide variety of infections in human; ranging from trivial intertriginous infection to fatal candidemia [5]. Studies from India have reported candidemia prevalence rates from 6-18\% [6-10]. In India candidemia incidence varies from 0.24 to 34.3 patients $/ 1,000$ ICU admissions and mortality rate ranges from $35-45 \%$ [11-15].

Candida auris has recently set an alarming state worldwide with its rapid spread within hospitals and between hospitals worldwide. Due to its multidrug resistant nature and often misidentification; it causes a broad range of healthcare-associated invasive infections (HCAI). It forms an important cause of nosocomial outbreaks and factor contributing to the spread of C.auris is its propensity to persist on the surfaces of hospital rooms and on medical devices [16-18]. Recently, C.auris was found to be the second most prevalent species causing candidemia in a tertiary care trauma center in Delhi, India, warranting more effective infection control practices to prevent its spread [19].

Due to the close genetic relatedness with $C$. haemulonii complex, C.auris is often commonly misidentified as C.haemulonii in routine diagnostic laboratories using biochemical methods. In fact, commercially available biochemical-based tests, including API AUX 20C, VITEK-2 YST, BD Phoenix, and MicroScan, misidentifies C.auris as a wide range of Candida species and other genera. Misidentifications as C.famata, C.sake, Rhodotorula glutinis, Rhodotorula mucilaginosa, Saccharomyces, C. catenulate, C.lusitaniae, C.guilliermondii and C. parapsilosis have also been reported [20-22]. Recently, BioMérieux has updated the database [2324] and inclusion of C.auris spectra in the VITEK-2 system has led to its correct identification.
Frequent use of antifungal agents like fluconazole for prophylaxis \& therapy, use of broad spectrum antibiotics; has led to the change in the prevalence of the Candida species and emergence of less susceptible Candida species. Infections with NAC are on rise and there is increase in resistance to antifungal agents. Hence, this study is taken up to find out the distribution of different Candida species \& provide detailed database on the prevalence, distribution and antifungal susceptibility pattern of the Candida isolates against common antifungal agents used in a tertiary care hospital. This would help in better understanding of present scenario.

\section{Material and methods}

This is a one year prospective study, which was conducted from August 2016 to July 2017 in the Department of Microbiology at Krishna Institute of Medical Science, Secunderabad, India; after obtaining clearance from ethics committee on 9 August 2016 - The KIMS Foundation and Research center (KFRC/EC/2016/57-09). Samples submitted to the microbiology laboratory like blood, pus, fluids, tissues, etc. from inpatients with symptoms and clinical manifestations suggestive of Candida infection were included in the study. It included all patients with positive culture showing pure growth of Candida admitted in intensive care units (ICU), Organ transplantation units \& wards at KIMS Hospital, Secunderabad. Samples from outpatients department and samples like oral cavity wash, sputum, endotracheal secretions, bronchial wash, vaginal swabs \& urine from in-patients were excluded from this study. All the consecutive samples and samples with isolation of Candida from two different contiguous sites were included till the sample size was met.

Fluid, pus or tissue biopsy from affected site; blood sample in case of disseminated infections were collected during the study period and they were processed and cultured based on standard microbiological guidelines. Preliminary tests included macroscopic examination of samples and direct microscopic examination by Gram's staining. Potassium hydroxide (KOH) mount and Gomori's methanamine silver (GMS) staining was done for tissues and deep seated specimen. For blood cultures, BacT/ALERT blood culture automated system (BioMérieux) was used. Candida was isolated by doing culture on 5\% sheep blood agar (BA) and Sabouraud's dextrose agar (SDA) with antibiotic 
(chloramphenicol). Preliminary speciation was carried using germ tube test (GTT) \& culture on cornmeal agar (CMA) for observing chlamydospore formation. Finally isolated species were identified and confirmed using YST identification card of Vitek 2 compact system (BioMérieux). In Vitek, the identification level gives the confidence level with which an unknown bio pattern is compared. Various qualitative levels of identification (Excellent - 9699\% probability, Very good - 93-95\%, Good - 89$92 \%$, etc.) were assigned based on the numerical probability calculation. Isolates showing high confidence level were only included in this study. In case of rare species being identified, isolate was sent to referral mycology laboratory for final identification.

The antifungal susceptibility testing of all Candida isolates were done for fluconazole, voriconazole, amphotericin $\mathrm{B}$, caspofungin and micafungin by using AST-YS07/08 card in VITEK 2 compact system [25-27]. The susceptibility to the above antifungal drugs is considered based on MIC values according to CLSI guidelines based on standard methods in document M27-A3 for macrobroth and microtitre yeast testing \& M60 document [25, 28-30]. Final identification results were available in approximately 16-18 hours.

\section{Results}

KIMS is a 1000 bedded tertiary care hospital with its laboratory receiving samples from all specialties and super-specialties. Inpatients with symptoms and clinical manifestations suggestive of Candida infection admitted in ICU's, organ transplantation units \& wards were included in this study. Positive cultures showing pure growth of Candida from samples of patients with high clinical suspicion along with other associated factors and co-morbidities were only included. All the patient samples wherein Candida was isolated as a part of normal commensal or forms a part of colonization were excluded from the study. Only paired blood culture samples were included in the study. Clinical correlation was done for all the patients included in the study.

Total number of samples (blood, pus, fluids, central line tips, tissues, etc.) received during the study period for culture and sensitivity was 6326 . Culture positives out of total received samples were 1844
(29.1\%). Among them, 100 were cultures positive for Candida species. Hence, the prevalence of Candida infection in the present study is $1.58 \%$.

In this study of one year; only $25(25 \%)$ of the isolates were Candida albicans and rest 75(75\%) of the isolates were NAC (Figure 1).

Candida albicans $\quad$ Non-albicans Candida (NAC)

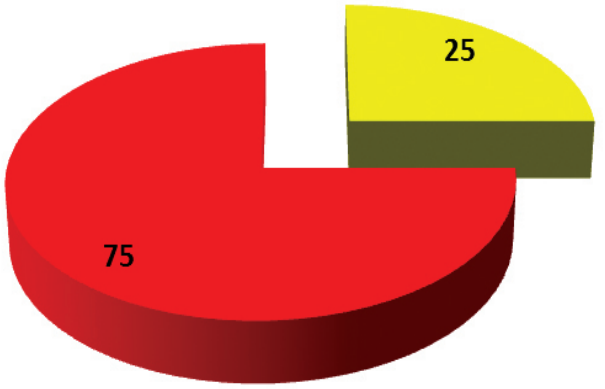

Figure 1: Percentage of Candida isolates.

Out of 75 NAC isolates (Figure 2), 46(61.33\%) were Candida tropicalis, 9(12\%) were C.hemulonii, 6(8\%) were C.glabrata, 4(5.33\%) C.famata, 4(5.33\%) C.parapsilosis, 2(2.66\%) were C.guilliermondii, $1(1.33 \%)$ was C.auris and others accounted for remaining 3(4\%) which included one isolate each of C.krusei, C.spherica and C.lusitaniae.

The features of identification of Candida spp. and variation by Gram's stain, germ tube test (GTT), cutstreak culture on cornmeal agar (CMA) and by Vitek 2 is shown in Table 1.

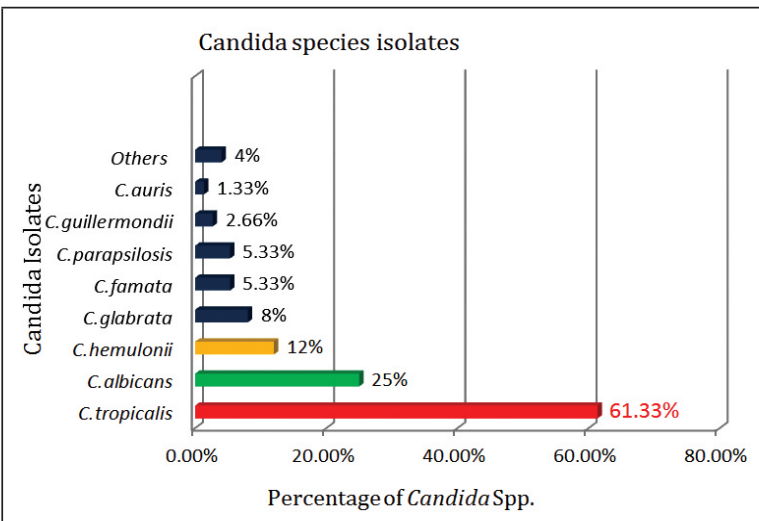

Figure 2a: Species-wise distribution of Candida.

Out of total 100 patients with candidiasis; 67(67\%) were male and 33(33\%) were female (Figure 3). The predominant age group (Figure 4) affected were adults 42\% (>30yrs) and elderly 40\% (>60yrs). 
Table 1: Features of various Candida spp., on Gram's stain, germ tube test (GTT), cut-streak culture on CMA \& Vitek.

\begin{tabular}{|c|c|c|c|c|c|c|}
\hline S.No & Candida spp. & Gram's stain & GTT & CMA & Vitek & Variations \\
\hline 1. & C.albicans (25) & $\begin{array}{l}\text { Spherical/ } \\
\text { sub-spherical } \\
\text { blastoconidia } \\
\sim 2-7 \times 3-8 \mu \mathrm{m}\end{array}$ & Positive & $\begin{array}{l}\text { Production of } \\
\text { pseudohyphae \& } \\
\text { chlamydospores } \\
\text { mostly terminal }\end{array}$ & $\begin{array}{l}\text { Identified as } \\
\text { C.albicans }\end{array}$ & Nil \\
\hline 2. & C.tropicalis (46) & $\begin{array}{l}\text { Spherical/ } \\
\text { sub-spherical } \\
\text { blastoconidia } \\
\sim 3-5.5 \times 4-9 \mu \mathrm{m}\end{array}$ & Negative & $\begin{array}{l}\text { Abundant branched, } \\
\text { long pseudohyphae } \\
\text { with many ovoid } \\
\text { blastoconidia }\end{array}$ & $\begin{array}{l}\text { Identified as } \\
\text { C.tropicalis }\end{array}$ & Nil \\
\hline 3. & C.hemulonii (9) & $\begin{array}{l}\text { Ovoid to spherical } \\
\text { blastoconidia } \\
\sim 3-5 \times 3-6.5 \mu \mathrm{m}\end{array}$ & Negative & $\begin{array}{l}\text { No pseudohyphae } \\
\text { produced Spherical to } \\
\text { ovoid budding yeasts } \\
\text { only }\end{array}$ & $\begin{array}{l}\text { Identified as } \\
\text { C.hemulonii }\end{array}$ & Nil \\
\hline 4. & C.glabrata (6) & $\begin{array}{l}\text { Ovoid blastoconidia } \\
\sim 3.4 \times 2.0 \mu \mathrm{m}\end{array}$ & Negative & $\begin{array}{l}\text { No pseudohyphae } \\
\text { or chlamydospores } \\
\text { produced } \\
\text { Ovoid budding yeasts } \\
\text { only }\end{array}$ & $\begin{array}{l}\text { Identified as } \\
\text { C.glabrata }\end{array}$ & Nil \\
\hline 5. & C.famata (4) & $\begin{array}{l}\text { Ovoid blastoconidia } \\
\sim 3.5 \times 2-3.5 \mu \mathrm{m}\end{array}$ & Negative & $\begin{array}{l}\text { No pseudohyphae } \\
\text { produced Spherical to } \\
\text { ovoid budding yeasts } \\
\text { only }\end{array}$ & $\begin{array}{l}\text { Identified as } \\
\text { C.famata }\end{array}$ & Nil \\
\hline 6. & C.parapsilosis (4) & $\begin{array}{l}\text { Small spherical to } \\
\text { ovoid blastoconidia } \\
\sim 2-3.5 \times 3-4.5 \mu \mathrm{m}\end{array}$ & Negative & $\begin{array}{l}\text { Abundant branched } \\
\text { pseudohyphae with } \\
\text { blastoconidia in small } \\
\text { clusters arranged like } \\
\text { "Spider colonies" }\end{array}$ & $\begin{array}{l}\text { Identified as } \\
\text { C.parapsilosis }\end{array}$ & Nil \\
\hline 7. & C.guilliermondii (2) & $\begin{array}{l}\text { Spherical/ } \\
\text { sub-spherical } \\
\text { blastoconidia } \\
\sim 2-4 \times 3-6 \mu \mathrm{m}\end{array}$ & Negative & $\begin{array}{l}\text { Branched } \\
\text { pseudohyphae with } \\
\text { dense blastoconidia }\end{array}$ & $\begin{array}{l}\text { Identified as } \\
\text { C.guilliermondii }\end{array}$ & Nil \\
\hline 8. & C.auris (1) & $\begin{array}{l}\text { Ovoid blastoconidia } \\
\sim 2-5 \times 3-7 \mu \mathrm{m}\end{array}$ & Negative & $\begin{array}{l}\text { Budding yeast cells } \\
\text { only. } \\
\text { No Pseudohyphae }\end{array}$ & $\begin{array}{l}\text { Identified as } \\
\text { C.auris in blood }\end{array}$ & $\begin{array}{l}\text { Misidentified } \\
\text { as C.famata } \\
\text { and } \\
\text { C.hemulonii in } \\
\text { other samples }\end{array}$ \\
\hline 9. & C.krusei (1) & $\begin{array}{l}\text { Small ovoid } \\
\text { blastoconidia } \\
\sim 2-5.5 \times 4-11 \mu \mathrm{m}\end{array}$ & Negative & $\begin{array}{l}\text { Abundant } \\
\text { long, branched } \\
\text { pseudohyphae with } \\
\text { ovoid blastoconidia }\end{array}$ & $\begin{array}{l}\text { Identified as } \\
\text { C.krusei }\end{array}$ & Nil \\
\hline 10. & C.lusitaniae (1) & $\begin{array}{l}\text { Ovoid blastoconidia } \\
\sim 1.5-6 \times 2.5-10 \mu \mathrm{m}\end{array}$ & Negative & $\begin{array}{l}\text { Abundant branched } \\
\text { pseudohyphae with } \\
\text { ovoid blastoconidia }\end{array}$ & $\begin{array}{l}\text { Identified as } \\
\text { C.lusitaniae }\end{array}$ & Nil \\
\hline
\end{tabular}

Among male and females; predominant age-group affected was 40-60 years in males whereas in females predominant age-group affected was 60$80 y r s$ in women. 

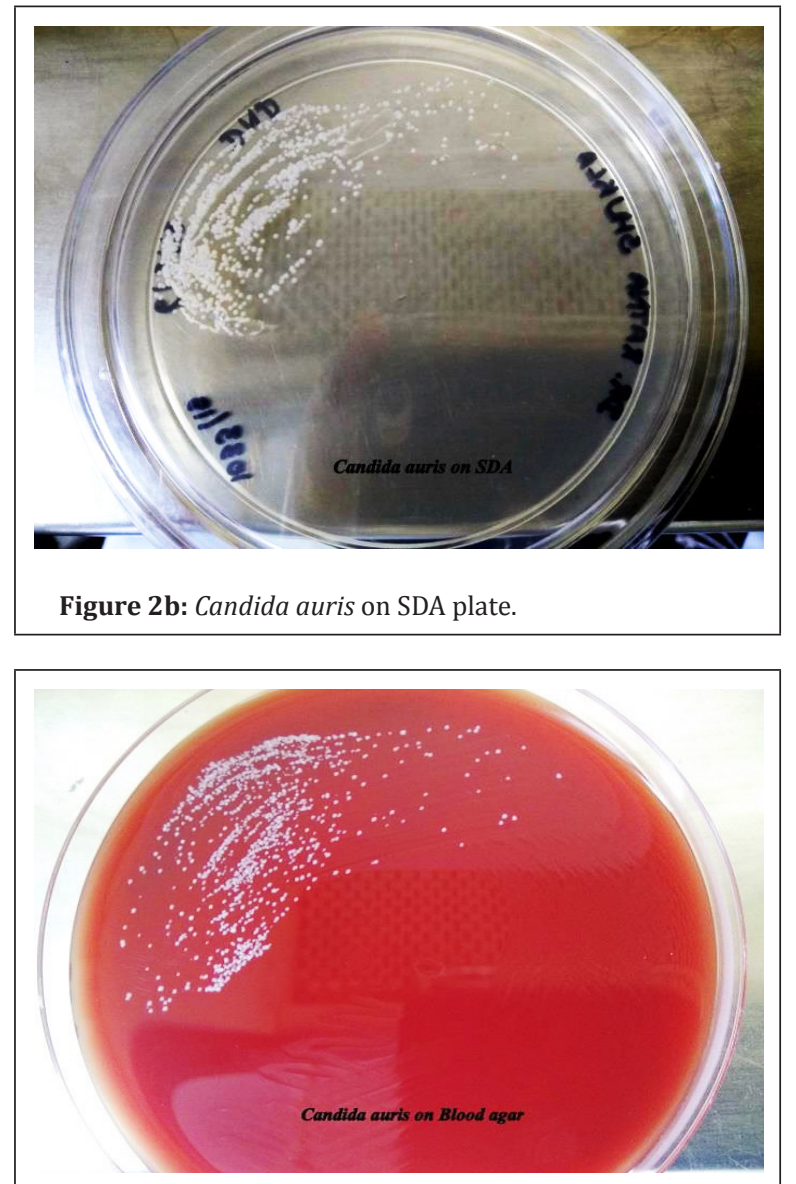

Figure 2c: Candida auris on blood agar.
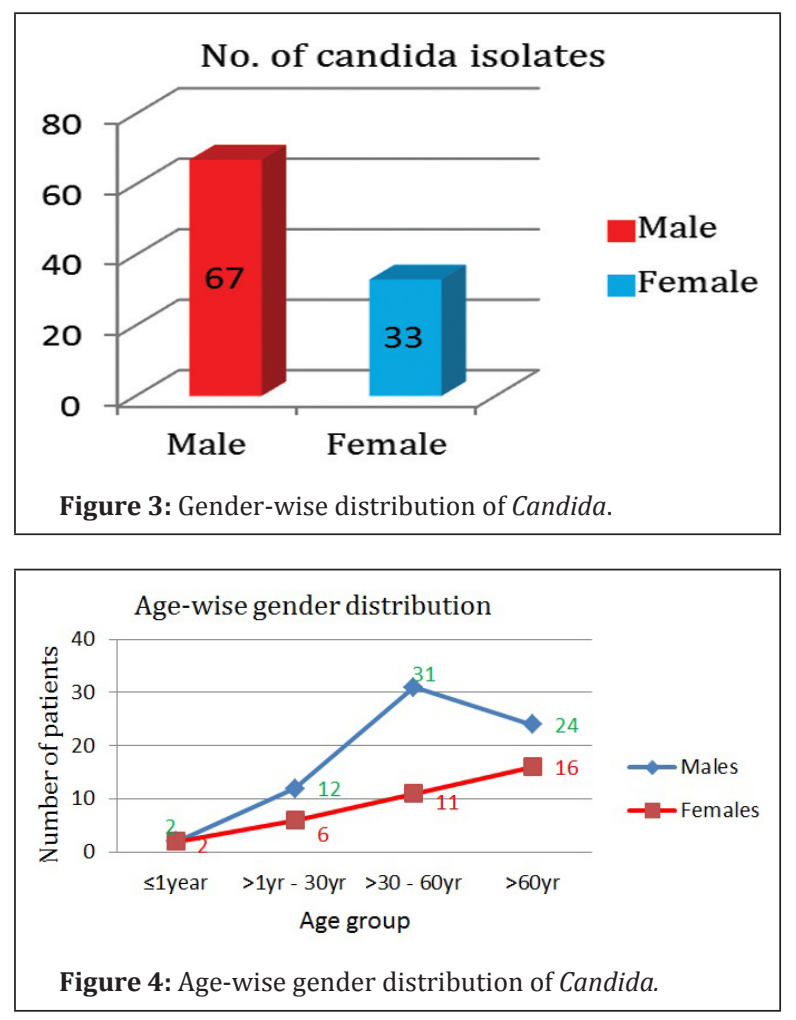

Among various samples (Figure 5) included in this study, maximum Candida isolates were seen in Blood (75\%) followed by Pus (9\%), Central line tips (4\%), Pleural fluid (4\%) and others (8\%)

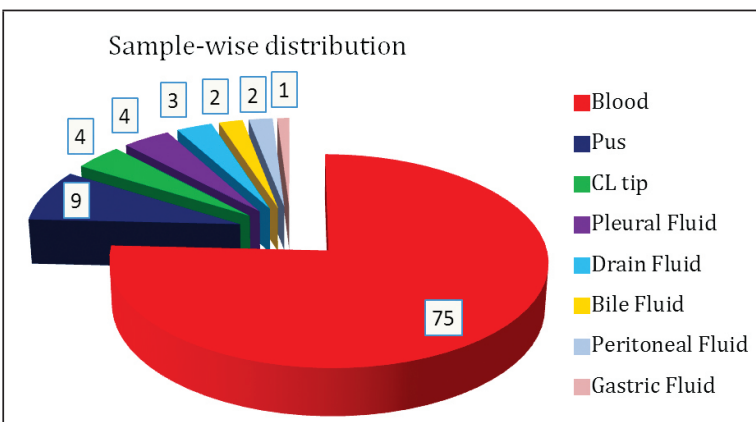

Figure 5: Sample-wise distribution of Candida.

Among candidemia cases, NAC (76\%) were predominating; most common isolate being Candida tropicalis ( $50 \%$ ). Out of total 75 isolates of Candida in blood; 37(49.33\%) were C.tropicalis, $18(24 \%)$ were C.albicans followed by $8(10.64 \%)$ - C.hemulonii, 4(5.33\%) - C.glabarata, 3(4\%) C.famata, 3(4\%) - C.parapsilosis and single isolate of each C.auris (1.33\%) and C.guilliermondii (1.33\%). The distribution of Candida spp. in blood is shown in Figure 6.

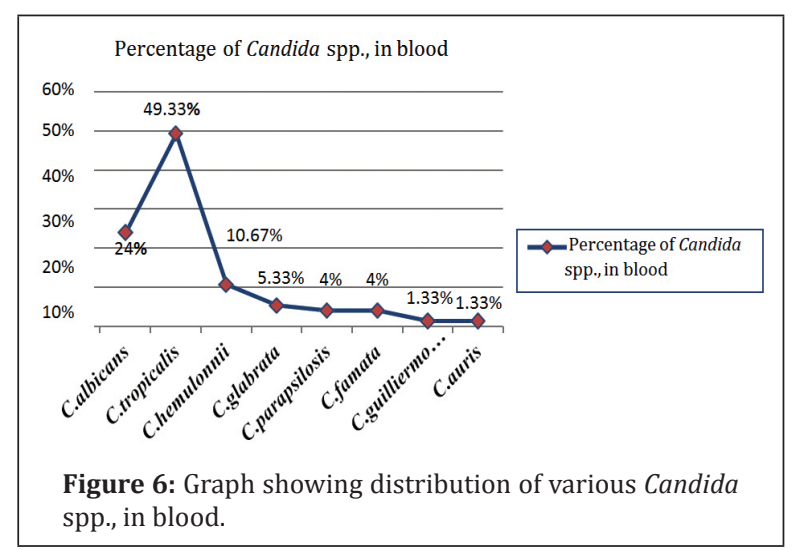

The antifungal susceptibility among Candida albicans isolates for fluconazole was $80 \%$ as compared to NAC; which showed only $53.3 \%$ susceptibility (Figures 7\&8). Susceptibility towards amphotericin B was relatively less in NAC $(74.66 \%)$ isolates as compared with Candida albicans (84\%) isolates.

The resistance was highest for fluconazole (46.7\%) followed by AMB (25.3\%) among NAC isolates. Similarly in Candida albicans isolates, highest resistance was seen with fluconazole (20\%) followed 
by AMB (16\%). In this study, the susceptibility towards all the group of antifungal drugs was seen more with Candida albicans in comparison with NAC (Figure 9).
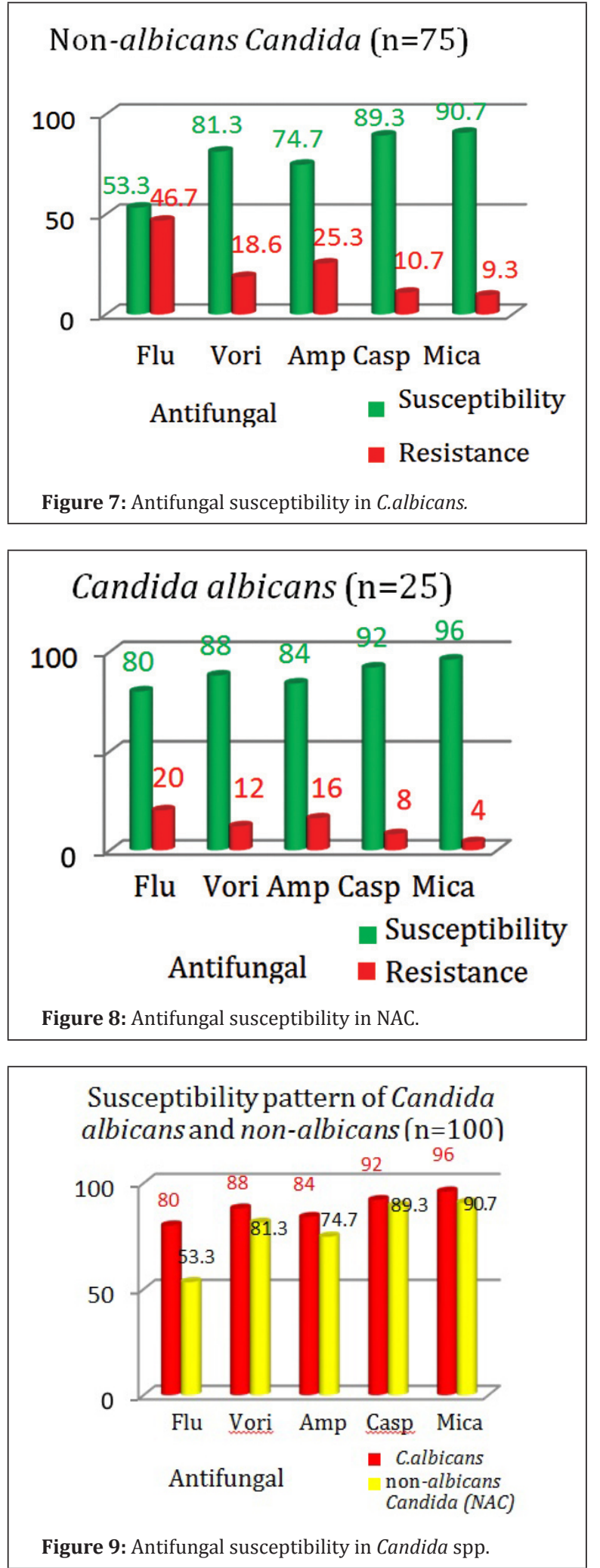

All the Candida isolates were maximally susceptible to Echinocandin group of antifungals. Among NAC species, C.tropicalis showed decreased susceptibility towards azoles group of antifungals. C.famata (4) isolates were seen sensitive to all the group of antifungals except one isolate which showed resistance to fluconazole. A special pattern was observed in all the C.hemulonii isolates (9). All patients with C.hemulonii infection showed similar pattern of antifungal susceptibility (Table 2) wherein they were all sensitive to Voriconazole, Caspofungin and Micafungin. All the 9 C.hemulonii isolates were resistant to fluconazole and amphotericin $B$. All rare NAC species (C.hemulonii, C.auris, C.krusei, C.spherica and C.lusitaniae) showed resistance to fluconazole whereas C.parapsilosis showed decreased susceptibility to polyene and echinocandin group of antifungals.

Table 2: Antifungal susceptibility pattern among Candida isolates.

\begin{tabular}{|lccccc|}
\hline $\begin{array}{l}\text { Susceptibility of } \\
\begin{array}{l}\text { Candida isolates } \\
\text { in percentage \% } \\
\text { (n=100) }\end{array}\end{array}$ & Flu & Vori & $\begin{array}{c}\text { Amp } \\
B\end{array}$ & Casp & Mica \\
\hline $\begin{array}{l}\text { Candida } \\
\text { tropicalis (46) }\end{array}$ & 65.2 & 82.6 & 89.1 & 89.1 & 89.1 \\
Candida albicans (25) & 80 & 88 & 84 & 92 & 96 \\
$\begin{array}{l}\text { Candida } \\
\text { hemulonii (9) }\end{array}$ & 0 & 77 & 0 & 88 & 100 \\
$\begin{array}{l}\text { Candida glabrata (6) } \\
\text { Candida famata (4) }\end{array}$ & 33 & 66 & 100 & $100 *$ & 100 \\
$\begin{array}{l}\text { Candida } \\
\text { parapsilosis (4) }\end{array}$ & 100 & 100 & 50 & 75 & 75 \\
$\begin{array}{l}\text { Candida } \\
\text { guilliermondii (2) }\end{array}$ & 50 & 50 & 50 & 50 & 50 \\
Candida auris (1) & 0 & 0 & 0 & 100 & 100 \\
Candida krusei (1) & 0 & 100 & 100 & 100 & 100 \\
Candida spherica (1) & 0 & 100 & 0 & 100 & 100 \\
$\begin{array}{l}\text { Candida } \\
\text { lusitaniae (1) }\end{array}$ & 0 & 100 & 100 & 100 & 100 \\
\hline
\end{tabular}

*Candida glabrata is $100 \%$ susceptible/intermediate to caspofungin based on revised guidelines [30].

Diabetes mellitus (46\%) was the most common predisposing factor noticed among patients with Candida infection (Table 3). This was followed 
by hypertension (34\%), use of broad spectrum antibiotics (31\%) and any recent major surgery $(22 \%)$. Long duration of hospital stay ( $\geq 14$ days) was seen in $90 \%$ of patients with other co-morbidities and associated Candida infection.

There were four liver transplantation cases with candidemia. Candida hemulonii (50\%) was the major isolate. Other two liver transplant cases had candidemia with Candida auris (25\%) and Candida tropicalis (25\%). Mortality among these organ transplantation patients was $75 \%$.

Table 3: Factors associated with Candida Infection.

\begin{tabular}{|lc|}
\hline Associated factors & $\begin{array}{c}\text { No. of patients } \\
\text { affected }\end{array}$ \\
\hline DM & 46 \\
HTN & 34 \\
Broad spectrum antibiotics & 31 \\
Major surgery & 22 \\
Carcinoma (GI and hematological & 15 \\
malignancy) & 14 \\
Autoimmune diseases & 11 \\
CKD & 10 \\
Chemotherapy & 9 \\
Corticosteroids & 8 \\
Central line & 8 \\
CLD & 7 \\
Radiotherapy & 6 \\
Immunosuppressants & 4 \\
Liver transplantation & \\
\hline
\end{tabular}

Out of total 100 patients in this study (Figure 10); $15 \%$ belonged to the pediatrics group. $20 \%$ patients out of all adults belonged to pulmonary medicine department followed by nephrology (17.64\%), gastro-surgery (14.11\%) and oncology (14.11\%) department. Hematological and gastrointestinal malignancies formed the major part among oncology patients.

In this study, out of total 100 patients with candidiasis (Figure 11); 41 patients got treated, 28 patients with Candida infection and associated multiple co-morbidities expired. In drug sensitive candidiasis cases with both C.albicans and NAC, Tab/ Inj. fluconazole was the most common drug used for treatment with duration of treatment ranging from 7-14 days. In drug resistant cases, Inj.Micafungin/ Inj.Voriconazole/Inj.AMB was used depending on the susceptibility test results and patient condition. Duration of treatment ranged from 5-10 days. The outcome was favorable in cases wherein, early treatment was started.

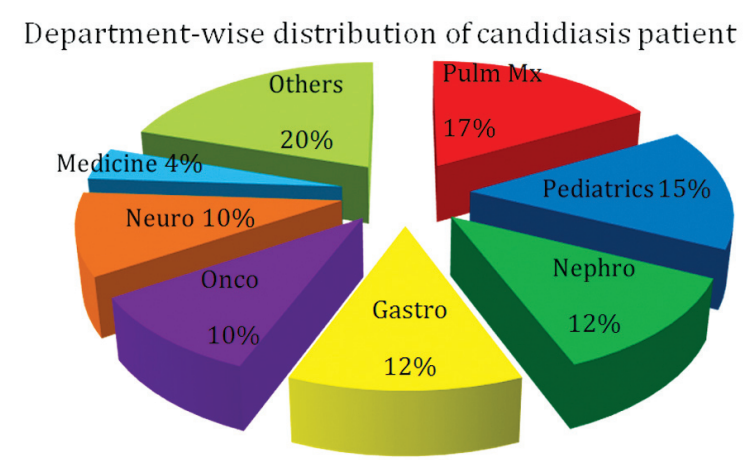

Figure 10: Graph showing department-wise distribution of candidiasis patients.

The mortality of $32.6 \%$ (Table 4 ) was seen in case of drug-resistant Candida isolates. Mortality and morbidity was higher in drug-resistant cases of Candida infection. In pan drug resistant cases, mortality reached up to $50 \%$. Better outcome was seen in drug sensitive cases. But this is only relative outcome.

Table 4: Patient outcome* in Candida infection.

\begin{tabular}{|c|c|c|c|c|}
\hline Outcome & Treated & Expired & $L A M A$ & $\begin{array}{c}\text { Status } \\
\text { unknown }\end{array}$ \\
\hline $\begin{array}{l}\text { Drug- } \\
\text { sensitive } \\
\text { Candida } \\
\text { isolates (50) }\end{array}$ & $\begin{array}{c}22 \\
(44 \%)\end{array}$ & $\begin{array}{c}11 \\
(22 \%)\end{array}$ & $\begin{array}{c}8 \\
(16 \%)\end{array}$ & $\begin{array}{c}9 \\
(18 \%)\end{array}$ \\
\hline $\begin{array}{l}\text { Drug- } \\
\text { resistant } \\
\text { Candida } \\
\text { isolates } \\
\text { [Resistant to } \\
\geq 1 \text { antifungal } \\
\text { drug] (46) }\end{array}$ & $\begin{array}{c}19 \\
(41.3 \%)\end{array}$ & $\begin{array}{c}15 \\
(32.6 \%)\end{array}$ & $\begin{array}{c}4 \\
(8.69 \%)\end{array}$ & $\begin{array}{c}8 \\
(17.39 \%)\end{array}$ \\
\hline $\begin{array}{l}\text { Pan resistant } \\
\text { Candida } \\
\text { isolates (4) }\end{array}$ & - & $2(50 \%)$ & $2(50 \%)$ & - \\
\hline
\end{tabular}

*Includes multiple associated factors and co-morbidities in addition to Candida infection.

True picture of outcome is based on multiple associated factors and debilitating co-morbidities 
like diabetes mellitus, underlying malignancy, major surgeries, immunosuppression, organ transplantation, chronic diseases (c/c kidney, liver or lung diseases), etc. and general conditions of patients along with Candida infection. Highest mortality was seen in pan-drug resistant cases. The mortality due to Candida infection was higher in case of infections caused by NAC (71.42\%). The major attributers to this were C.tropicalis (42.85\%) followed by C.albicans (28.57\%) and others (C.hemulonii10.7\%, C.glabrata-7.14\%, C.auris, C.parapsilosis \& C.guilliermondii- each $3.6 \%$ ).

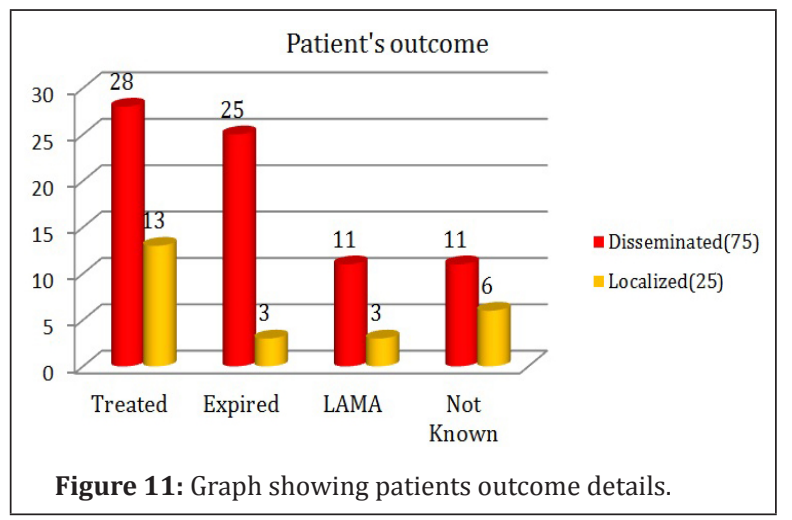

\section{Discussion}

This current study details the prevalence of Candida infection and their antifungal susceptibility pattern in a tertiary care hospital in South India. The prevalence of Candida infection in this study is $1.58 \%$, which shows comparable results with studies conducted by Gandhi et al. [31], Ahmedabad; Soumya et al. [5], Rodriguez et al. [32] in Peru.

Candida forms a part of normal human microbiota. It causes opportunistic infections in immunocompromised and debilitated patients. In this study, the predominant age group of patients affected with candidiasis belongs to the elderly group. Similar results were seen in a study conducted by Bhattacharjee et al. [33] in Kolkata and Liu et al. [34], Taiwan. In this study, only 25(25\%) of the isolates were Candida albicans and rest 75(75\%) of the isolates were NAC which shows similar trend in other studies [5, 11, 31, 32]. Whereas in contrast, Candida albicans formed the major isolate in studies conducted by Khan et al. [35], Amar et al. [36], Liu et al. [34] and Orasch et al. [37].

The predominant Candida species among NAC in present study is Candida tropicalis as seen with studies conducted by Bhatacharjee et al. [33] and
Chakrabarty et al. [11]. In contrast, in studies conducted by Western countries; Candida glabrata and Candida parapsilosis formed the predominant NAC species [32, 37-39].

One NAC isolate was Candida auris in the present study which was multi-drug (MDR) resistant. It was isolated from both blood and bronchial wash of a liver transplantation patient. On repeated test by Vitek 2 compact, this organism was misidentified as Candida famata twice. As this organism is put on high alert by CDC owing to its high mortality and MDR nature leading to difficult treatment; we confirmed the identity of the organism by sending it to reference laboratory at Mycology department, PGIMER, Chandigarh. Confirmation was done there using MALDI TOF automated system. Eventually even with effective parenteral treatment due to disseminated infection and immunocompromised state, the patient succumbed to death [40-42].

In the present study, gender predominance of Candidiasis infection was seen in males (67\%) as seen in other studies [31-33]. Among various samples included in this study, maximum Candida isolates were seen in blood $(75 \%)$ showing disseminated infection is common with Candida in susceptible individuals. Hence, early identification and prompt treatment based on the Candida speciation and its antifungal susceptibility is of utmost importance. Similar results were substantiated in various other studies conducted by Khan et al. [35], Jaggi et al. [10] and Dharwad et al. [43].

The antifungal susceptibility in present study for fluconazole among Candida albicans isolates was higher as compared to NAC. Study by Bhatacharjee et al. [33] shows similar results. This shows the importance of maintaining the rational use of antifungals. The choice of antifungal drug depends on various factors like local epidemiology and the patient's co-morbidities.

The emergence of NAC spp. has initiated the need of antifungal susceptibility testing of Candida isolates. The NAC species are comparatively less susceptible to fluconazole and amphotericin B [28, 33]. Candida krusei shows intrinsic resistance to fluconazole [5, 44]. This was justified in present study. All rare NAC species (Candida hemulonii, Candida auris, Candida krusei, Candida spherica and Candida lusitaniae) 
showed higher resistance to fluconazole. Candida albicans and Candida tropicalis showed 16\% and 10.8\% resistance to Amphotericin B, respectively in this study. Studies conducted by Nazir et al. [45], Sandhu et al. [46] and international studies by Jamil et al. [47] and Badiee et al. [48] shows similar results. In another study conducted by Bhattacharjee et al. [33], further high resistance was seen in Candida albicans and Candida tropicalis against amphotericin B. In contrast, various other studies shows very low or nil resistance to amphotericin B [5, 28, 32, 43, 49-50]. Many studies show amphotericin B testing as not applicable. This is because detection of resistance to amphotericin B by the CLSI M27A2 BMD method has been problematic due to the very narrow range of MICs obtained [51-53]. This implies that further research and studies are needed to standardize polyene testing for yeasts. C.parapsilosis showed decreased susceptibility to polyene and echinocandin group of antifungals. Maximum susceptibility towards all the antifungal groups was seen by Candida famata in this study. Novel finding in present study was that among Candida hemulonii isolates (9); all patients with Candida hemulonii infection showed similar pattern of antifungal susceptibility. They were all sensitive to Voriconazole, Caspofungin and Micafungin but all 9 Candida hemulonii isolates were resistant to fluconazole and amphotericin B. This could be indicative of evolving intrinsic resistance to FLU and AMB but this information needs further research owing to limited number of isolates to come to any conclusion.

Azole drugs still remain a safe and effective choice for treatment for mild to moderate Candida infection, as it is available in both parenteral and oral formulations with high bioavailability. Irrational use of fluconazole for prophylaxis and treatment and prolonged duration or incomplete treatment could be the reasons of present emergence of high drug resistance to fluconazole.

The availability of new fungal markers, such as betad-glucan, has opened the door to research in early therapy strategies such as empirical therapy in high risk hosts. But they are still under process of being standardized and needs more studies like this to support and direct in the empiric treatment of highrisk hosts.
In this study, the NAC shows better susceptibility to Echinocandin group of drugs also seen in other studies $[5,11]$. Patients who showed resistance to fluconazole and amphotericin B were treated with Echinocandin group of drugs; in most cases with Inj.Micafungin. Echinocandins are highly expensive and cannot be afforded by a majority of the Indian population. Hence, prevention of infection by improving the living status, nutrition and maintaining strict infection control in ICU's and wards in hospitals should be given higher importance.

\section{Strength of the study}

This is a prospective study and the sample size was calculated statistically. The samples like oral and vaginal swabs, urine, sputum, end otracheal secretion and bronchial wash were excluded from the study. Samples like blood, deep pus, fluids and tissues representing invasive and disseminated candidiasis were only included in this study. The final species identification and antifungal susceptibility testing was done by automated Vitek 2 compact system. This avoided manual errors of interpretations and those isolates with good identification were only included in the study.

\section{Limitations of the study}

Molecular methods and sequencing could not be done due to economic constraints. LAMA patients could not be followed up; hence the outcome could not be measured in those cases. This study has a limitation of a single institutions experience. Group of population are limited; hence generalizability of these findings to the settings with different patient populations is the limitation of this study. Amphotericin B resistant isolates were not checked using microbroth dilution method which is gold standard method.

\section{Future directions}

Further studies assessing the predisposing factors, species level identification and involving larger group of population affected with candidiasis are recommended. Regular surveillance of local antifungal susceptibility patterns and formulation of empiric treatment guidelines for high risk patients is suggested.

\section{Conclusion}

There is a significant epidemiological shift in 
candidiasis cases due to NAC species. This is due to the advanced treatment and diagnostic interventions. Candida tropicalis is the most frequent pathogen isolated in our tertiary care center. Candida albicans and NAC both shows reduced susceptibility to azoles mainly fluconazole; but NAC shows higher decrease in susceptibility pattern towards azoles. Candida albicans still shows good susceptibility towards polyene group and echinocandins. NAC shows decreased susceptibility to polyene as compared to C.albicans. Echinocandins forms better empirical choice in invasive NAC infections but choice of azoles or echinocandins differs based on severity of infection and individual patient condition. Based on the present results and trends, it becomes essential to routinely identify Candida isolates at species level, and detect evolving resistant strains by antifungal susceptibility test. Furthermore, there is a continued need for surveillance to monitor changes in the epidemiological features and antifungal susceptibility and also to develop and evaluate prevention strategies

\section{Acknowledgement}

Department of Microbiology, KIMS Hospital, Secunderabad, India.

\section{Conflict of interest}

Authors declare no conflict of interest.

\section{References}

[1] Segal E, Elad D. Candidiasis. In: Merz WG, Hay RJ, Topley Wilson's - Microbiology and microbial infection. 10th ed. Medical mycology: London: Hodder Arnold; 2007:579-613.

[2] Butler G, Rasmussen MD, Lin MF, Santos MAS, Sakthikumar $\mathrm{S}$, et al. Evolution of pathogenicity and sexual reproduction in eight Candida genomes. Nature. 2009; 459:657-662.

[3] Pfaller MA, Diekema DJ, Epidemiology of invasive candidiasis: a persistent public health problem. Clin Microbiol Rev. 2007; 20(1):133-163.

[4] Centers for Disease Control and Prevention. Candidiasis. USA: 2015 June. Available from: https://www.cdc.gov/ fungal/diseases/candidiasis/

[5] Sowmya GS, Kulkarni M, Gopalakrishnan R. Speciation and antifungal susceptibility pattern of Candida isolates in a tertiary care hospital. Int J Adv Sci Technol. 2014; 2(3):1218.

[6] Magill SS, Shields C, Sears CL, Choti M, Merz WG. Triazole cross-resistance among Candida spp.: case report, occurrence among bloodstream isolates, and implications for antifungal therapy. J Clin Microbiol. 2006; 44(2):529-535.

[7] Xess I, Jain N, Hasan F, Mandal P, Banerjee U. Epidemiology of candidemia in a tertiary care centre of north India: 5-year study. Infection. 2007; 35(4):256-259.
[8] Kothari A, Sagar V. Epidemiology of Candida bloodstream infections in a tertiary care institute in India. Indian J Med Microbiol. 2009; 27(2):171-182.

[9] Edwards JE. Candidiasis. In: Kasper DL, Fauci AS, editors. Harrison's infectious diseases. 1st ed. McGraw-Hill Education books; 2010. pp. 1017-1021.

[10] Jaggi T, Urhekar AD, Pai C, Hodiwala AB, Gore S, et al. Study of Candida species in various clinical samples in a tertiary care hospital. DHR Int J Med Sci. 2014; 5(2):83-88.

[11] Chakrabarti A, Sood P, Rudramurthy SM, Chen S, Kaur H, et al. Incidence, characteristics and outcome of ICU-acquired candidemia in India. Intensive Care Med. 2014; 41(2):285295.

[12] Meyer E, Geffers C, Gastmeier P, Schwab F. No increase in primary nosocomial candidemia in 682 German intensive care units during 2006-2011. Euro Surveill. 2013; 18(24):20505.

[13] Gonzalez de Molina FJ, Leon C, Ruiz-Santana S, Saavedra P, the CAVAI Study Group. Assessment of candidemia-attributable mortality in critically ill patients using propensity score matching analysis. Crit Care. 2012; 16(3):R105

[14] Nolla-Salas J, Sitges-Serra A, Leon-Gil C, Martínez-González J, León-Regidor MA, et al. Candidemia in non-neutropenic critically ill patients: analysis of prognostic factors and assessment of systemic antifungal therapy. Study group of fungal infection in the ICU. Intensive Care Med. 1997; 23(1):23-30.

[15] Charles PE, Doise JM, Quenot JP, Aube H, Dalle F, et al. Candidemia in critically ill patients: difference of outcome between medical and surgical patients. Intensive Care Med. 2003; 29(12):2162-2169.

[16] Cortegiani A, Misseri G, Fasciana T, Giammanco A, Giarratano A, et al. Epidemiology, clinical characteristics, resistance, and treatment of infections by Candida auris. J Intensive Care. 2018; 6:69.

[17] Welsh RM, Bentz ML, Shams A, Houston H, Lyons A, et al. Survival, persistence, and isolation of the emerging multidrug-resistant pathogenic yeast Candida auris on a plastic health care surface. Journal of clinical microbiology. 2017; 55(10):2996-3005.

[18] Eyre DW, Sheppard AE, Madder H, Moir I, Moroney R, et al. A Candida auris outbreak and its control in an intensive care setting. N Engl J Med. 2018; 379(14):1322-1331.

[19] Chakrabarti A, Sood P, Rudramurthy SM, Chen S, Kaur H, et al. Incidence, characteristics and outcome of ICU-acquired candidemia in India. Intensive Care Med. 2015; 41:285295.

[20] Kathuria S, Singh PK, Sharma C, Prakash A, Masih A, et al. Multidrug-resistant Candida auris misidentified as Candida haemulonii: characterization by matrix-assisted laser desorption ionization-time of flight mass spectrometry and DNA sequencing and its antifungal susceptibility profile variability by Vitek 2, CLSI broth microdilution, and Etest method. J Clin Microbiol. 2015; 53:1823-1830.

[21] Kim TH, Kweon OJ, Kim HR, Lee M-K. Identification of uncommon Candida species using commercial identification systems. J Microbiol Biotechnol. 2016; 26:2206-2213.

[22] Jeffery-Smith A, Taori SK, Schelenz S, Jeffery K, Johnson EM, et al. Candida auris: a review of the literature. Clin Microbiol Rev. 2018; 31:e00029-17.

[23] Girard V, Mailler S, Chetry M, Vidal C, Durand G, et al. Identification and typing of the emerging pathogen Candida auris by matrix-assisted laser desorption ionisation time of flight mass spectrometry. Mycoses. 2016; 59:535-538. 
[24] Mizusawa M, Miller H, Green R, Lee R, Durante M, et al. Can multidrug-resistant Candida auris be reliably identified in clinical microbiology laboratories? J Clin Microbiol. 2017; 55:638-640.

[25] CLSI. Reference method for broth dilution antifungal susceptibility testing of yeasts; approved standard-3rd ed. CLSI document M27-A3. Clinical and Laboratory Standards Institute, Wayne. 2008; 28(14).

[26] Fothergill AW. Antifungal susceptibility testing: clinical laboratory and standards institute (CLSI) methods. In: Interactions of yeasts, moulds, and antifungal agents: How to detect resistance. 2013; pp.65-71.

[27] Charan J, Biswas T. How to calculate sample size for different study designs in medical research? Indian J Psychol Med. 2013; 35(2):121-128.

[28] Deorukhkar SC, Saini DS. Species distribution and antifungal susceptibility profile of Candida species isolated from blood stream infections. J Evol Med Dent Sci. 2012; 1(3):241-249.

[29] Sastry AS, SB K, Sastry AS, Kumudavathi MS. Characterization and susceptibility pattern of Candida isolates from hiv seropositive patients in a tertiary care hospital. J Evol Med Dent Sci. 2012; 1(4):589-597.

[30] CLSI. Performance Standards for Antifungal Susceptibility Testing of Yeasts. 1st ed. CLSI Supplement M60. Wayne, PA: Clinical and Laboratory Standards Institute; 2017.

[31] Gandhi V, Patel M. Prevalence of Candida species and its antifungal susceptibility isolated from blood culture at tertiary care hospital, Ahmedabad, India. Int J Curr Microbiol Appl Sci. 2017; 6(6):884-892.

[32] Rodriguez L, Bustamante B, Huaroto L, Agurto C, Illescas R, et al. A multicentric study of Candida bloodstream infection in Lima-Callao, Peru: Species distribution, antifungal resistance and clinical outcomes. PLoS One. 2017; 12(4):1-12.

[33] Bhattacharjee P. Epidemiology and antifungal susceptibility of Candida species in a tertiary care hospital, Kolkata, India. Curr Med Mycol. 2016; 2(2):20-27.

[34] Liu W, Lai C, Li M, Wu CJ, Ko WC. Clinical manifestations of candidemia caused by uncommon Candida species and antifungal susceptibility of the isolates in a regional hospital in Taiwan, 2007-2014. J Microbiol Immunol Infect. 2019; 52(4):612-619.

[35] Khan PA, Fatima N, Nabeela, Jahan S, Khan HM, et al. Antifungal susceptibility pattern of Candida isolates from a tertiary care hospital of north India: A Five Year Study. Int J Curr Microbiol App Sci. 2015; Special Issue-1:177-181.

[36] Amar CS, Mahalakshmi VV, Vinay H. Prevalence and antifungal susceptibility of Candida species isolated from patients attending tertiary care hospital. IOSR J Dent Med Sci. 2014; 5(2):44-49.

[37] Orasch C, Marchetti O, Garbino J, Schrenzel J, Zimmerli S, et al. Candida species distribution and antifungal susceptibility testing according to European committee on antimicrobial susceptibility testing and new vs. old clinical and laboratory standards institute clinical breakpoints: a 6-year prospective candidaemia survey from the fungal infection network of switzerland. Clin Microbiol Infect. 2014; 20(7):698-705.

[38] Nanjappa SG, Klein BS. Vaccine immunity against fungal infections. Curr Opin Immunol. 2014; 28:27-33.

[39] Cruciani M, Serpelloni G. Management of Candida infections in the adult intensive care unit. Expert Opin Pharmacother. 2008; 9(2):175-191.
[40] Chowdhary A, Sharma C, Meis JF. Candida auris: A rapidly emerging cause of hospital-acquired multidrugresistant fungal infections globally. PLoS Pathog. 2017; 13(5):e1006290.

[41] Prakash A, Sharma C, Singh A, Kumar Singh P, Kumar A, et al. Evidence of genotypic diversity among Candida auris isolates by multilocus sequence typing, matrix-assisted laser desorption ionization time-of-flight mass spectrometry and amplified fragment length polymorphism. Clin Microbiol Infect. 2016; 22(3):277.e1-9.

[42] Kathuria S, Singh PK, Sharma C, Prakash A, Masih A, et al. Multidrug-resistant Candida auris misidentified as Candida haemulonii: characterization by matrix-assisted laser desorption ionizationtime of flight mass spectrometry and DNA sequencing and its antifungal susceptibility profile variability by Vitek 2, CLSI Broth Microdilution, and Etest method. J Clin Microbiol. 2015; 53(6):1823-1830.

[43] Dharwad S, Saldanha DRM. Species identification of Candida isolates in various clinical specimens with their antifungal susceptibility patterns. J Clin Diagnostic Res. 2011; 5(6):1177-1181.

[44] Wu J, Zhu L, Ou X, Xu BIN, Hu X, et al. Epidemiology and risk factors for non59 Candida albicans candidemia in nonneutropenic patients at a Chinese teaching hospital. 2018; 49(5):552-555.

[45] Nazir A, Masoodi T. Spectrum of Candida species isolated from neonates admitted in an Intensive Care Unit of teaching hospital of Kashmir, North India. Journal of Laboratory Physicians. 2018; 10(3):255-259.

[46] Sandhu R, Dahiya S, Sayal P, Budhani D. Increased role of nonalbicans Candida, potential risk factors, and attributable mortality in hospitalized patients. Journal of Health Research and Reviews. 2017; 4(2):78-83.

[47] Jamil B, Mukhtar Bokhari MT, Saeed A, Mukhtar Bokhari MZ, Hussain Z, et al. Candidiasis: Prevalence and resistance profiling in a tertiary care hospital of Pakistan. J Pak Med Assoc. 2017; 67(5):688-697.

[48] Badiee P, Badali H, Boekhout T, Diba K, Moghadam AG, et al. Antifungal susceptibility testing of Candida species isolated from the immunocompromised patients admitted to ten university hospitals in Iran: comparison of colonizing and infecting isolates. BMC Infectious Diseases. 2017; 17(1):1-8.

[49] Guru P, Raveendran G. Characterisation and antifungal susceptibility profile of Candida species isolated froma tertiary care hospital. Journal of the Academy of Clinical Microbiologists. 2016; 18(1):32-35.

[50] Adhikary R, Joshi S. Species distribution and anti-fungal susceptibility of Candidaemia at a multi super-specialty center in Southern India. Indian J Med Microbiol. 2011; 29:309-311.

[51] Park BJ, Arthington-Skaggs BA, Hajjeh RA, Iqbal N, Ciblak MA, et al. Evaluation of amphotericin B interpretive breakpoints for Candida bloodstream isolates by correlation with therapeutic outcome. Antimicrob. Agents Chemother. 2006; 50(4):1287-1292.

[52] Rex JH, Pfaller MA. Has antifungal susceptibility testing come of age? Clin Infect Dis. 2002; 35(8):982-989.

[53] Rex JH, Pfaller MA, Walsh TJ, Chaturvedi V, Espinel-Ingroff A, et al. Antifungal susceptibility testing: practical aspects and current challenges. Clin Microbiol Rev. 2001; 14(4):643658. 